\title{
Aluminum Polyphosphate Gels Structural Evolution Probed by NMR Spectroscopy
}

\author{
André Galembeck* \\ Departamento de Química Fundamental, Universidade Federal de Pernambuco, 50670-901 Recife - PE, Brazil
}

\begin{abstract}
Neste trabalho é apresentada a evolução estrutural de géis de polifosfato de alumínio, desde a associação das espécies que leva à gelatinização, e prosseguindo pelas etapas de envelhecimento e secagem. As alterações nas espécies formadoras da rede foram acompanhadas por RMN de ${ }^{31} \mathrm{P}$ e ${ }^{27} \mathrm{Al}$, tanto em solução quanto no estado sólido. Verificou-se que as cadeias de polifosfato maiores é que dão a contribuição preponderante para a formação do gel e que as unidades de ortofosfato e os oligômeros menores são expulsos da rede durante a sinérese. Durante a formação e o envelhecimento dos géis ocorre hidrólise, que leva à quebra das cadeias e diminuição no seu tamanho médio. Amostras envelhecidas em ambientes com alta umidade relativa tendem a absorver água e isso contribui para que as reações de hidrólise ocorram de forma pronunciada, tornando-se líquidos viscosos. Por outro lado, as amostras expostas a umidades relativas da ordem de $20 \%$ tornam-se sólidos quebradiços em que as cadeias maiores tendem a se manter estáveis. Amostras secas a vácuo apresentam ainda aproximadamente $30 \%$ de água em sua estrutura.
\end{abstract}

The aim of this work was to investigate how the structure of aluminum polyphosphate gels change upon aging and drying. This is essential if one is interested in using a gel as a matrix to synthesize organic-inorganic hybrid materials. The liquid and solid samples were characterized by ${ }^{27} \mathrm{Al}$ and ${ }^{31} \mathrm{P}$ NMR spectroscopy. Larger polyphosphate chains make the main contribution to gel formation and the smaller units are expelled into the supernatant solution. Polyphosphate chains undergo hydrolysis and chain scission upon gelation. Samples aged in a moisture-rich environment turn into viscous liquids as a consequence of water uptake, followed by extensive hydrolysis. Samples exposed to low relative humidity environments dry yielding brittle samples in which larger chains are stable. Vacuum-dried samples still contain ca. 30\%-weight water.

Keywords: polyphosphate gels, ${ }^{31} \mathrm{P} \mathrm{NMR},{ }^{27} \mathrm{Al} \mathrm{NMR}$, aluminum polyphosphate, sol-gel

\section{Introduction}

The sol-gel process is based on the concept of molecular manipulation to design ceramics, glasses, and composites. ${ }^{1}$ The low temperature process allows for the incorporation of guest organic molecules within the inorganic matrix, as well as for the synthesis of hybrid networks in which the organic and inorganic phases are interpenetrating. The so-called organic-inorganic hybrid nanocomposites may present properties that do not depend solely on each component individually, but also on interface phenomena between these phases, which can lead to synergistic effects. ${ }^{2}$ Therefore, one can get control over mechanical, optical and electrical properties which are specially designed at the molecular level. ${ }^{3,4}$ Polyphosphate association to aluminum or calcium ions in aqueous

\footnotetext{
* e-mail: andre@ufpe.br
}

solution can lead to gelation under appropriate conditions. ${ }^{5}$ The mechanism of aluminum polyphosphate (APP) gelation was investigated by NMR spectroscopy by Montagne et al., which reported gel formation at phosphorus to aluminum molar ratio higher than 2.8 and identified $\mathrm{Al}^{3+}$ complexes with two and three phosphate ligands as the species responsible for gelation. ${ }^{6}$ Lima and Galembeck reported a phase diagram in which gel formation at room temperature occur in the $2.0<\mathrm{P} / \mathrm{Al}<$ 3.0 range. $^{7}$

As gelation proceeds due to the association of polyphosphate polyanions and $\mathrm{Al}^{3+}$ ions, the system cohesion results from electrostatic interactions and hydrogen bonding, rather than the covalently bonded network that develops upon hydrolysis and polycondensation of alkoxide precursors. ${ }^{1}$ Aluminum polyphosphate gels were, hence, defined as supramolecular ionic disordered swollen networks ${ }^{7}$ that do not fit in the classification proposed by Flory. ${ }^{8}$ 
Transparent aluminum polyphosphate hydrogels may be synthesized at room temperature. They can be processed into fibers, flexible self-standing films and small monoliths, thus, providing a suitable path to new sol-gel based materials. Metal to polyphosphate association provides also alternative routes to synthesize phosphate glasses ${ }^{9}$ and colloidal particles. ${ }^{10}$

We have recently reported the entrapment of a rareearth cryptate within the APP gel, which was the first hostguest structure based on this matrix. It may be seen as a three level supramolecular architecture where the rare-earth ion is entrapped within the cryptand cage, which is, in turn, entrapped within the polyphosphate network. The emission spectrum of the terbium cryptate within the APP gel network showed narrower lines than those observed in aqueous solution. This was ascribed to the restricted environment provided by the gel network. ${ }^{11}$ Polyphosphate/organic dye composites sensitive to acidic and basic vapors were also prepared successfully by the incorporation of methyl orange and malachite green within the APP network. ${ }^{12,13}$

NMR spectroscopy investigations on aluminum polyphosphate gel formation is well documented in the literature, but there are neither reports of solid state NMR measurements nor data dealing with the structural changes during aging and drying. ${ }^{6,7}$ This information is essential if one is interested in making polyphosphate based hybrid nanocomposites for solid state optical and electro-optical devices.

\section{Experimental}

Reagent grade aluminum nitrate $\left(\mathrm{Al}\left(\mathrm{NO}_{3}\right)_{3} \cdot 9 \mathrm{H}_{2} \mathrm{O}\right.$, Merck), sodium polyphosphate (NaPP, Nuclear) and sodium hydroxide (Merck) were used as purchased.

\section{Aluminum Polyphosphate (APP) Gel Synthesis}

APP gels were prepared starting from $2.0 \mathrm{~mol} \mathrm{~L}^{-1}$ sodium polyphosphate $(\mathrm{NaPP})$ and $1.0 \mathrm{~mol} \mathrm{~L}^{-1} \mathrm{Al}\left(\mathrm{NO}_{3}\right)_{3}$ aqueous solutions. Polyphosphate average chain length was 10.6, calculated from the ${ }^{31} \mathrm{P}-\mathrm{NMR}$ spectrum of a NaPP aqueous solution. Phosphorus to aluminum ratio was within the 2.0-3.0 range and a $5.0 \mathrm{~mol} \mathrm{~L}^{-1} \mathrm{NaOH}$ aqueous solution was eventually added in order to increase the $\mathrm{pH}$.

The solutions were mixed under strong stirring and gelation proceeds within $1 \mathrm{~min}$, leading to a white selfstanding gel. This was crushed, stirred for $30 \mathrm{~min}$ and stored for $24 \mathrm{~h}$. Within this period, the gel settles down and undergoes synerisis separating from the supernatant liquid that was drained every $24 \mathrm{~h}$. The gel becomes transparent after 3 to 20 days, depending on the actual $\mathrm{P} / \mathrm{Al}$ ratio, $\mathrm{pH}$ and temperature.

Some samples were submitted to centrifugation at $10,000 \mathrm{~g}$ immediately after gelation, in order to speed up phase separation prior to ${ }^{31} \mathrm{P}$ and ${ }^{27} \mathrm{Al}$ NMR measurements.

Transparent samples were aged at room environment, in closed vials at RT, as well as within moisture-controlled boxes or dried under dynamic vacuum. The weight changes were followed as a function of time.

\section{Characterization}

NMR $\left({ }^{31} \mathrm{P}\right.$ and $\left.{ }^{27} \mathrm{Al}\right)$ spectra were acquired using a Varian UNITY plus 300 spectrometer, operating at $121.42 \mathrm{MHz}$ phosphorus frequency, and at $78.16 \mathrm{MHz}$ for aluminum. The reported chemical shifts are relative to $85 \% \mathrm{H}_{3} \mathrm{PO}_{4}$ and $\left[\mathrm{Al}\left(\mathrm{H}_{2} \mathrm{O}\right)_{6}\right]^{3+}$ for phosphorus and aluminum, respectively. The samples were studied in solution and in the solid state with magic angle spinning (MAS-NMR).

Thermogravimetric analysis was carried out in a Shimadzu 50-WS equipment from room temperature up to $800{ }^{\circ} \mathrm{C}$, at $10^{\circ} \mathrm{C} \mathrm{min}{ }^{-1}$ heating rate, under a $50 \mathrm{~mL} \mathrm{~min}^{-1}$ nitrogen flux.

\section{Results}

\section{Gelation}

In order to identify the chemical species that contribute to the gel network formation and those which tend to be expelled in the supernatant solution, sample centrifugation was carried out to get a fast separation between supernatant solution and gel phases. The ${ }^{27} \mathrm{Al}$ and ${ }^{31} \mathrm{P}$ NMR spectra presented in Figures 1 and 2 refer to the gel and to the liquid (supernatant solution) phases separated by centrifugation from a mixture prepared with a $2.5 \mathrm{P} / \mathrm{Al}$ molar ratio. These spectra were acquired using solution probe.

The sharp peak at $\delta 0$ in Figure 1 arises from $\left[\mathrm{Al}\left(\mathrm{H}_{2} \mathrm{O}\right)_{6}\right]^{3+}$. When phosphate groups coordinate to aluminum ions the chemical shifts are $\delta-3.5$ $\left(\left[\mathrm{Al}\left(\mathrm{H}_{2} \mathrm{O}\right)_{5} \mathrm{PO}_{3}\right]^{2+}\right), \delta-6.6\left(\left[\mathrm{Al}\left(\mathrm{H}_{2} \mathrm{O}\right)_{4}\left(\mathrm{PO}_{3}\right)_{2}\right]^{+}\right)$and $\delta-10$ $\left(\left[\mathrm{Al}\left(\mathrm{H}_{2} \mathrm{O}\right)_{3}\left(\mathrm{PO}_{3}\right)_{3}\right]\right)$, respectively, resulting from the shielding effect that $\mathrm{PO}_{3}^{-}$ligands exert on $\mathrm{Al}^{3+}{ }^{6,14}$

Both spectra in Figure 1 present peaks, which can be ascribed to hexa-aquo aluminum ion and $\mathrm{Al}^{3+}$ complexes with one and two phosphate groups. Both spectra were deconvoluted assuming also a fourth signal at $\delta 10$ from $\left[\mathrm{Al}\left(\mathrm{H}_{2} \mathrm{O}\right)_{3}\left(\mathrm{PO}_{3}\right)_{3}\right]$. However, the best fits gave a fourth broad peak at $c a$. $\delta 6.0$ and 8.0 for the supernatant liquid and the gel, respectively, which were interpreted considering that there are mainly two types of $\left[\mathrm{Al}\left(\mathrm{H}_{2} \mathrm{O}\right)_{4}\left(\mathrm{PO}_{3}\right)_{2}\right]^{+}$species: $(i)$ 
$\mathrm{Al}^{3+}$ ions bound to two phosphate groups from the same chain (broader peak) and (ii) $\mathrm{Al}^{3+}$ ions bound to two $\left(\mathrm{PO}_{3}^{-}\right)$ from different chains (sharper peak). This results agree with that reported by Lima et al. ${ }^{14}$ and are summarized in Table 1.

In the spectrum of the supernatant liquid phase the hexa-aqua complex amount is highest $(17.68 \%)$ and the major contribution comes from aluminum bonded to two phosphate groups from the same chain $(67.21 \%$, Figure 1b). On the other hand, the gel spectrum (Figure 1a) presents only $1.85 \%$ of $\left[\mathrm{Al}\left(\mathrm{H}_{2} \mathrm{O}\right)_{6}\right]^{3+}$ and $\mathrm{Al}^{3+}$ bonded to phosphate groups from different chains is almost 50\% (4.67\% in the liquid phase).

This shows that the gel contains a large amount of PO3-A1-PO3 bridges but these are less important in the supernatant solution. It is consistent with the picture that a supramolecular network in which the polyanion chains interconnect by means of $\mathrm{Al}^{3+}$ ions must develop to give the gel and aluminum species that do not play this role are expelled to the supernatant solution.

The doublet at $c a . d 3.5$ in the liquid phase spectrum was previously assigned to Al-P coupling. ${ }^{14,15}$ No signal from $\mathrm{Al}$ bonded to three phosphate groups could be observed. Table 1 presents the percentage of each Al species identified in the spectra in Figure 1.

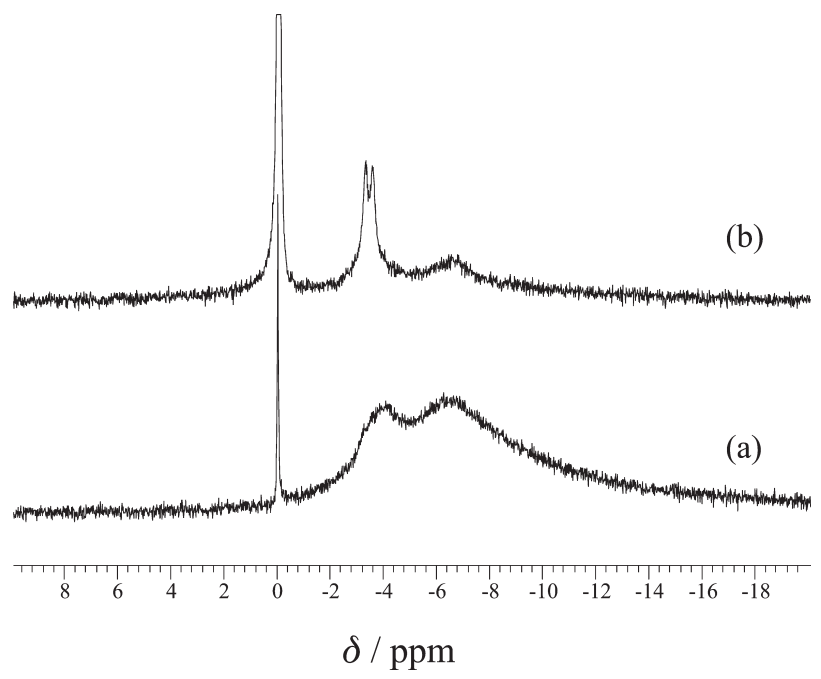

Figure 1. ${ }^{31} \mathrm{Al} \mathrm{NMR}$ spectra of an APP gel $(\mathrm{P} / \mathrm{Al}=2,5)$ centrifuged immediately after gelation. (a) gel; (b) liquid supernatant

The ${ }^{31} \mathrm{P}$ NMR spectra of the gel samples are very similar to those previously described in the literature (Figure 2). ${ }^{14,16}$ The spectrum of the gel sample shown in Figure $2 \mathrm{a}$ resembles those reported by Draoui et al., in which signals arising from free and Al-bonded orthophosphate and endchain phosphate groups are very weak. ${ }^{16}$ These peaks are readily detected in the spectrum of the supernatant liquid.
Table 1. Area fraction and position of the deconvoluted peaks from the ${ }^{27} \mathrm{Al}$ spectra.

\begin{tabular}{lllll}
\hline Sample & $\mathrm{Al}^{3+}$ & $\mathrm{AlP}$ & $\mathrm{AlP}_{2}{ }^{\mathrm{a}}$ & $\mathrm{AlP}_{2}^{\mathrm{b}}$ \\
\hline supernatant liquid & $17.68 \%$ & $10.44 \%$ & $67.21 \%$ & $4.67 \%$ \\
& $\delta-0.1$ & $\delta-3.5$ & $\delta-6.0$ & $\delta-6.56$ \\
gel & $1.85 \%$ & $17.47 \%$ & $30.86 \%$ & $49.82 \%$ \\
& $\delta 0.0$ & $\delta-3.8$ & $\delta 7.8$ & $\delta 6.4$ \\
\hline
\end{tabular}

$\mathrm{Al}^{3+}:\left[\mathrm{Al}\left(\mathrm{H}_{2} \mathrm{O}\right)_{6}\right]^{3+} ; \mathrm{AlP}:\left[\mathrm{Al}\left(\mathrm{H}_{2} \mathrm{O}\right)_{5} \mathrm{PO}_{3}\right]^{2+} ; \mathrm{AlP}_{2}:\left[\mathrm{Al}\left(\mathrm{H}_{2} \mathrm{O}\right)_{4}\left(\mathrm{PO}_{3}\right)_{2}\right]^{+}$

a two phosphate groups from the same chain, ${ }^{\mathrm{b}}$ two phosphate groups from the different chains.

Chemical shifts ranging from $\delta 0.63$ to 0.66 and $\delta-6.0$ to -8.0 were assigned to free and Al-bound orthophosphates ( $\mathrm{Q}^{0}$ groups), respectively. Polyphosphate chain end groups $\left(\mathrm{Q}^{1}\right)$ appear at $\delta-10.0$ (free chain) and from $\delta-12.0$ to -16.0 (Al-bound). ${ }^{14}$

Regarding to middle chain $\mathrm{Q}^{2}$ groups, Montagne et. al. stated that phosphorus atoms in a complex with one, two or three phosphate ligands present peaks at $\delta-33.5$, -27.7 and -23.5 , respectively. ${ }^{6}$ Lima et $a l .{ }^{14}$ and Galembeck $^{7}$ did not detect complexes with 3 phosphate groups in ${ }^{27} \mathrm{Al}$ NMR spectra, which was confirmed in this study.

The spectrum presented in Figure 2a (gel) presents two sharp lines at $\delta-20.5$ and -21.8 , which were ascribed to free $\mathrm{Q}^{2}$ phosphate groups. These signals were also observed in Figure 2b (supernatant solution), although much weaker. When phosphate groups are bonded to $\mathrm{Al}^{3+}$, the peaks are broader and appear at lower frequencies. ${ }^{6}$ Also, there is a large number of possible combinations in which an aluminum cation can be coordinated by two $\mathrm{PO}_{3}^{-}$species, from end and middle chain groups. Those bands appear in the $\delta-22.0$ to -36.0 range. ${ }^{14}$

The most important issue of these data is that middle chain phosphate groups are mainly detected in the gel, and supernatant liquid spectrum is dominated orthophosphate and chain end groups, showing that the main contribution to gel formation comes from the larger chains. Shorter chains and orthophosphate groups produced by polyphosphate hydrolysis in acidic media are expelled from the gel into the synerisis liquid.

\section{Aging}

In order to investigate how the gel structure changes with aging, the gel synthesis was performed without the centrifugation step. 24h after gelation the supernatant was poured off, a ${ }^{31} \mathrm{P}$ MAS-NMR gel spectrum was acquired every 24 hours and the results are displayed in Figure 3. The gel contracts and the syneresis liquid is expelled for 3 to 5 days. Afterwards the gel dries by water evaporation. A 


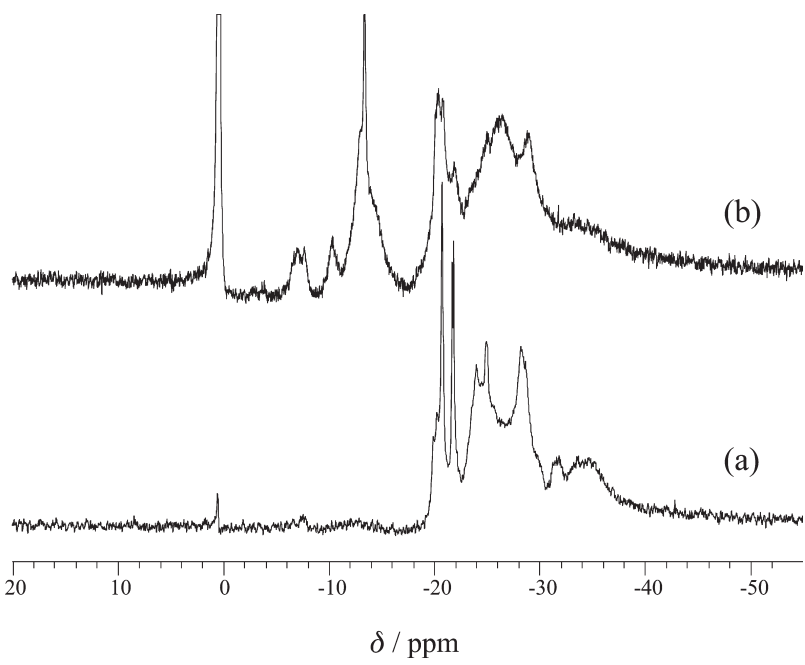

Figure2. ${ }^{27} \mathrm{P}$ NMR spectra of an APP gel $(\mathrm{P} / \mathrm{Al}=2,5)$ centrifuged immediately after gelation. (a) gel; (b) liquid supernatant.

$\mathrm{P} / \mathrm{Al}=2.5$ gel becomes transparent within 3 to 10 days.

The intensity of the peaks ascribed to orthophosphate and end-chain $\mathrm{Q}^{1}$ groups increases with time, followed by a decrease in the peaks assigned to middle-chain $\mathrm{Q}^{2}$ phosphate groups. This means that hydrolysis continues after gel formation and chains are still being broken as the gel is aged. Polyhosphate hydrolysis in acidic media is a well-known phenomenon. ${ }^{17,18}$

The sample shown in Figure 3 became transparent after 8 days. Transparency arises from synerisis and sample contraction to such an extent that the different domains within the gel matrix get small enough to produce only a low intensity of scattered light.

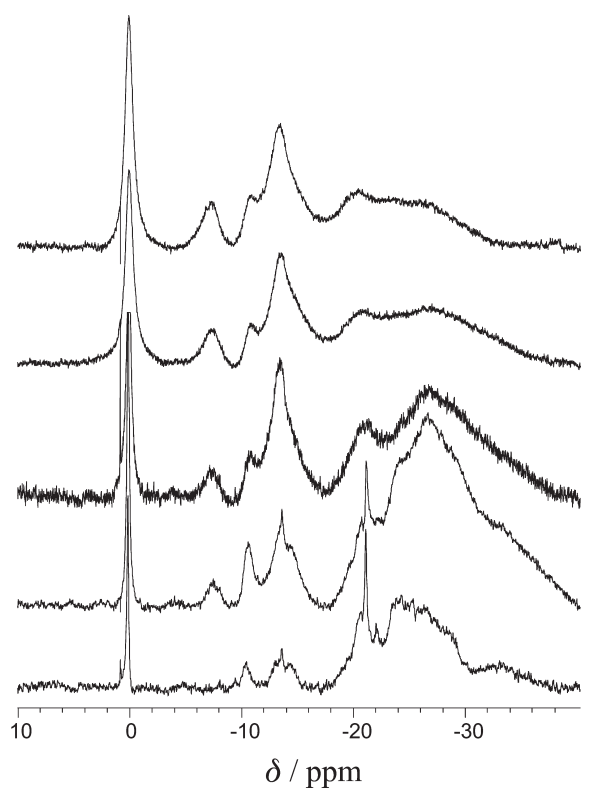

Figure 3. ${ }^{31} \mathrm{P}$ MAS-NMR spectra (solid state) of non-centrifuged aged APP gel. (a) 1 day; (b) 3 days; (c) 7 days; (d) 9 days; (e) 10 days.
When a $\mathrm{NaOH}$ solution was added during gel formation same behavior described above was observed but the hydrolysis rate of the polyphosphate chains was lowered as a consequence of the higher $\mathrm{pH}$ (results not shown).

Drying

Transparent samples were dried under three conditions; (i) room environment; (ii) closed vials; (iii) moisture controlled boxes.

When a transparent sample is exposed to room environment, a weight loss due to water evaporation is observed within the first 12 to 24 hours. After this period the gel weight shows good correlation with the environment relative humidity ( $\mathrm{RH})$, as shown Figures 4a and 4b. Data in Figure 4b were collected within a three month period.
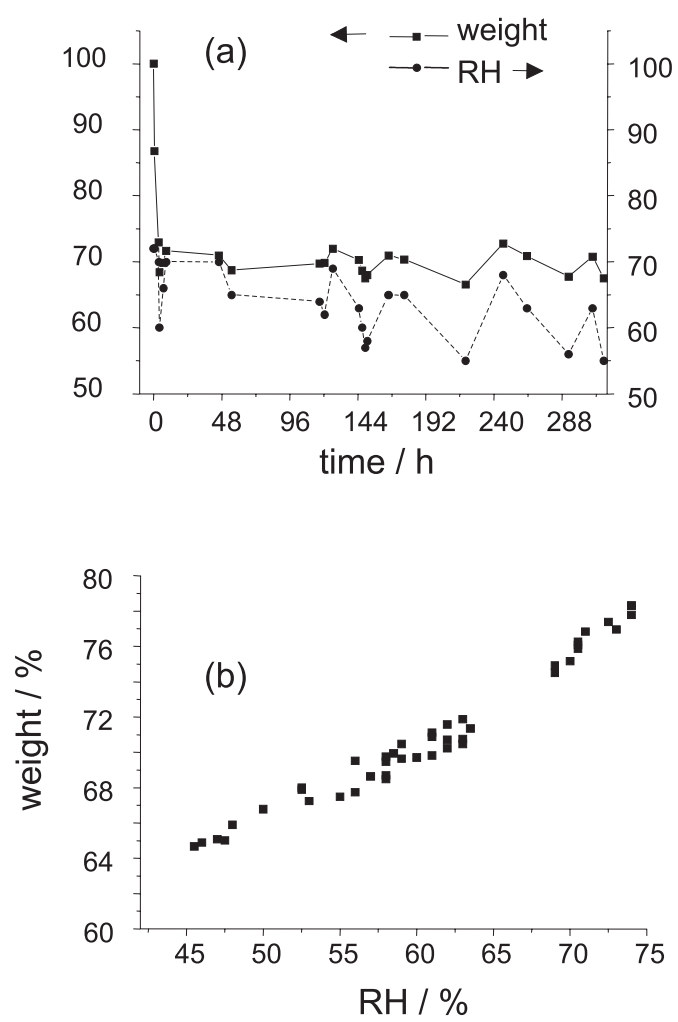

Figure 4. Drying APP gel at room environment. (a) sample weight and relative humidity $(\mathrm{RH})$ as a function of time; (b) sample weight as a function of relative humidity (data collected during three months).

In contrast, samples stored in closed vials undergo a viscosity decrease after transparency is achieved and turn into a viscous liquid after about a week, showing that hydrolysis continues under storage but there is no further synerisis.

Finally, when the samples were stored in boxes with constant relative humidity, a weight loss is observed during 
24 to 36 hours and a steady weight is reached. The lower the relative humidity, the higher is the weight loss as shown by the results presented in Figure 4. Samples with $\mathrm{P} / \mathrm{Al}=$ 2.0 exposed to $18 \%, 50 \%$ and $80 \%$ relative humidity stabilized after losing $35.0,30.0$ and $17.5 \%$ weight losses, respectively.

Figure 5 presents ${ }^{31} \mathrm{P}$ NMR spectra for APP gel $(\mathrm{P} / \mathrm{Al}=2.0)$ aged at $18 \%$ and $100 \%$ (saturated) RH for one week and 6 months respectively. The former is a brittle solid and the later is a viscous liquid.

The sample dried at $18 \% \mathrm{RH}$ for one week presents very broad peaks. The main contribution to ${ }^{31} \mathrm{P}$ spectra arises from Al-bonded middle-chain $\mathrm{Q}^{2}$ groups, ranging from $\delta-18$ to -40 . Free and Al-bound orthophosphate appear at $\delta 0$ and -8 , respectively, and Al-bonded chain end, $\mathrm{Q}^{1}$, at $d-14$. This means that hydrolysis is prevented in a low humidity environment.

The sample aged at humid atmosphere presents two peaks centered at $\delta 0$ and -8 , a shoulder at $\delta-10$ and a small peak at $\delta-16$. This means that hydrolysis occurred extensively as the spectrum is dominated by the orthophosphate peaks, both free and Al-bonded.

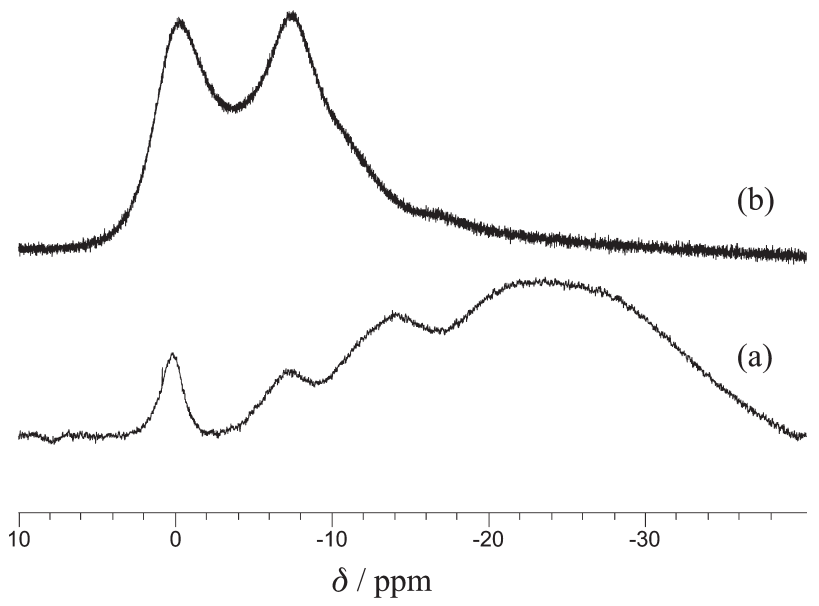

Figure 5. ${ }^{31} \mathrm{P}$ NMR spectra of aged APP gel at; (a) $18 \%$ relative humidity environment and (MAS-NMR); (b) water saturated environment (liquid sample).

One can summarize these results in the following way: hydrolysis occurs thoroughly if the water content in the gel is near $80 \%$ and the gel viscosity decreases as a consequence of extensive chain scission and water uptake. On the other hand, samples aged at $18 \%$ RH become brittle glasses and the gel network remains unchanged as water is evaporated.

When aluminum polyphosphate gel samples are dried under dynamic vacuum for 48 hours they cracked and turned into a hygroscopic powder. These samples were characterized by thermogravimetry, as shown in Figure
$6 \mathrm{a}$. Figure $6 \mathrm{~b}$ refers to a gel aged under $50 \%$ relative humidity. In both thermograms, there are two weight loss events ascribed to water elimination. Two important features appear: (i) the solid retains water up to $600{ }^{\circ} \mathrm{C}$, and (ii) vacuum dried samples still present $c a$. 30\%-weight water, which is strongly attached to the solid network. The transparent self-standing samples of aluminum polyphosphate gels aged at $50 \%$ relative humidity environment contain $c a .50 .0 \%$-weight water, as shown in Figure 6b.

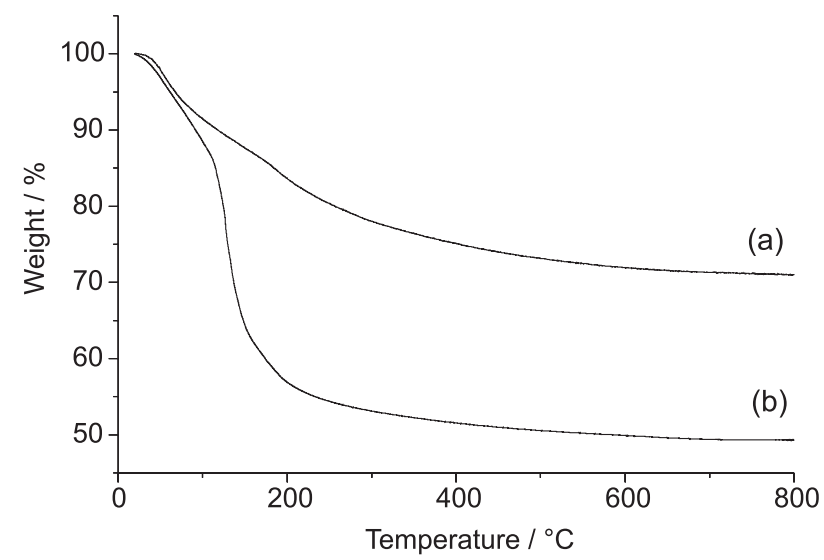

Figure 6. Thermogravimetric analysis. (a) APP gel dried under dynamic vacuum for 3 days; (b) fresh transparent APP gel.

\section{Conclusion}

High resolution and MAS-NMR measurements reveal the structural changes undergone during aluminum polyphosphate gel formation, aging and drying. Larger polyphosphate chains make the main contribution to gel formation, but they are hydrolyzed upon aging when exposed to a moist environment. Samples aged upon 18\% relative humidity turn into brittle glassy transparent solids, rich in polyphosphate ions but with a low orthophosphate content. These results explain the great ability of AlPP gels and glasses to include cationic species.

\section{Aknowledgements}

The author thanks the Brazilian Government Initiative in Nanoscience, as a member of the Molecular and Interface Nanoscience and Nanotechnology Network (RENAMI/ $\mathrm{CNPq}$ ) and also to the Millenium Institute of Complex Materials $\left(\mathrm{IM}^{2} \mathrm{C}\right) / \mathrm{CNPq} / \mathrm{MCT}$.

\section{References}

1. Hench, L.L.; West, J.K.; Chem. Rev. 1990, 90, 33. 
2. Sanchez, C.; Soler-Illia, G.J. de A.A.; Ribot, F.; Lalot, T.; Mayer, C.R.; Cabuil, V.; Chem. Mater 2001, 12, 3061.

3. Keeling-Tucker, T.; Brennan, J.D.; Chem. Mater. 2001, 13, 3331.

4. Costela, A; Garcia-Moreno, I.; Gomez, C.; Garcia, O; Sastre, R.; Appl. Phys. B-Lasers Optics 2002, 75, 827.

5. Draoui, M.; Vast, P.; Palavit, G.; Rev. Ch. Min. 1985, 22, 256.

6. Montagne, L. ; Palavit, G.; Draoui, M.; J. Non-Cryst. Solids 1993, 155, 115.

7. Lima, E.C.O.; Galembeck, F.; J.Colloid Interface Sci. 1994, 166, 309.

8. Flory, P.J.; Faraday Discuss. Chem. Soc. 1974, 57, 7.

9. Palavit, G.; Montagne, L.; Delaval, R.; J. Non-Crystalline Solids 1995, 189, 277.

10. Lima, E.C.O.; Beppu, M.M.; Galembeck, F.; Valente Filho, J.F.; Soares, D.M..; J. Braz. Chem. Soc. 1996, 7, 209.

11. Galembeck, A. ; Amorim, M.S.; Bazin, H.; Mathis, G.; Donegá, C. M.; Sá, G.F.; Alves-Jr, S.; Mol. Cryst. Liq. Cryst. 2002, 374, 267.
12. Galembeck, A.; Silva, S.B.C.; Silva, J.A.P.; Del Nero, J.; Opt. Mat. 2003, in press.

13. Del Nero, J.; Silva, J.A.P.; Silva, S.B.C.; Galembeck, A.; Synth. Met. 2003, 135, 157.

14. Lima, E.C.O.; Moita Neto, J.M.; Galembeck, F.; Fujiwara, F.Y.; J.Colloid Interface Sci. 1995, 176, 388.

15. Delpuech, J.J.; Khaddar, M.R., Peguy, A.A.; Rubini, P.R.; J. Am. Chem. Soc., 1975, 97, 3373.

16. Draoui, M.; Aomari, K., Saidi Idrissi, M.; Benarafa, L.; Mairesse, G.; Palavit, G.; Montagne, L; Can. J. Anal. Sci. Spec.1998, 43, 19.

17. MacDonald, J.C.; Mazurek, M; J. Magn. Res. 1987, 72, 48.

18. Mortlock, R.F.; Bell, A.T.; Radke, C.J.; J. Phys. Chem. 1993, 97, 775 .

Received: May 9, 2003

Published on the web: December 5, 2003 